ECCOMAS

\section{Proceedia}

COMPDYN 2021

$8^{\text {th }}$ ECCOMAS Thematic Conference on Computational Methods in Structural Dynamics and Earthquake Engineering M. Papadrakakis, M. Fragiadakis (eds.) Streamed from Athens, Greece, 28 - 30 June 2021

\title{
EFFICIENCY OF SEISMIC LIQUEFACTION MITIGATION METHODS FOR EXISTING STRUCTURES
}

\author{
Alexandros I. Valsamis ${ }^{1}$, Taxiarchoula G. Limnaiou ${ }^{1}$ and Achilleas G. Papadimitriou ${ }^{1}$ \\ ${ }^{1}$ School of Civil Engineering, National Technical University of Athens \\ 9 Iroon Polytechniou Street, Zographou, 15780, Greece \\ e-mails: a_valsamis@hotmail.com, tlimnaiou@gmail.com, apapad@civil.ntua.gr
}

\begin{abstract}
This paper investigates numerically the seismic liquefaction-induced "failure" mechanisms of elongated structures founded on the ground surface of a liquefiable sandy layer, which is first considered horizontal and then having a mild inclination angle of $2^{\circ}$. In accordance with the literature, the paper shows that if the layer is horizontal, the structure suffers from accumulation of settlement. It also shows that even such a mild inclination leads to the additional hazard of horizontal displacement and rotation of the structure due to lateral spreading of its foundation soil. The paper continues with an investigation of the beneficial effects of implementing rows of prefabricated drains or diaphragm walls at the perimeter of the foundation soil of these structures. The former mitigation method aims at reducing the developing excess pore pressures, while the latter targets at increasing the equivalent stiffness of the foundation system. The study is performed via non-linear dynamic fully coupled plane strain analyses with the finite-difference method, while the soil response is modeled with NTUA-SAND, a sophisticated bounding surface plasticity model with verified ability of simulating the response of liquefiable granular soils. It shows that diaphragm walls are much more efficient in reducing settlements, horizontal displacements and rotations than prefabricated drains. However, this efficiency is fully attained only if their depth reaches the bottom of the liquefiable layer.
\end{abstract}

Keywords: Diaphragm Walls, Drains, Earthquakes, Foundation Failure, Ground Improvement, Liquefaction, Numerical Analysis

ISSN:2623-3347 (C) 2021 The Authors. Published by Eccomas Proceedia.

Peer-review under responsibility of the organizing committee of COMPDYN 2021.

doi: 10.7712/120121.8475.19074 


\section{INTRODUCTION}

Since 1964 when the Alaska and Niigata earthquakes occurred, liquefaction has been treated as one of the most severe geo-hazards for civil engineering structures. Nowadays, there exists a large number of soil improvement techniques for liquefaction mitigation, which can be easily used prior to construction in many variants (e.g., densification by vibro-flotation or dynamic compaction, grouting/mixing by deep soil mixing or compaction grouting, drainage and stiffening by gravel piles). Yet, at already developed sites, the majority of these techniques cannot be applied due to the inability to perform improvement works under the structure footprint, as well as due to the possibility of severely affecting the infrastructures or neighboring structures during these works (e.g., due to vibrations from densification techniques). More importantly, there is a significant gap of knowledge for the applicability of existing mitigation techniques in cases where lateral spreading of liquefied ground is anticipated, either due to small inclination of the ground surface (angles of $0.5^{\circ}$ to $6^{\circ}$ ), or due to free face proximity.

In this paper, a numerical investigation of the behavior of strip footings founded directly on a liquefiable soil layer is being presented, focusing initially on the differences between having a horizontal and a mildly inclined ground surface $\left(\right.$ angle of $\left.2^{\circ}\right)$. Then, the effectiveness of two different liquefaction mitigation techniques is being analyzed for horizontal and inclined ground surface conditions. Particularly, the investigation focuses on the application of rows of prefabricated drains or narrow diaphragm walls solely at the perimeter of the foundation. Such configurations may not sound ideal for mitigating the liquefaction hazard since they do not cover the footprint of the structures. However, they are the only configurations that may be readily implemented in existing structures that is our primary concern here. Moreover, there exist limited experimental evidence of the efficiency of such configurations, and this comes from dynamic centrifuge studies for drains [1] and diaphragm walls [2] only for horizontal ground conditions.

\section{NUMERICAL METHODOLOGY}

The numerical investigation is performed with the finite difference code FLAC [3] and its User-Defined-Model capability. Particularly, the constitutive model NTUA-SAND ([4], [5]) is used for the simulation of the liquefiable soil layer after its implementation in FLAC. It is a well-established bounding surface Critical State plasticity model, which has proven ability to simulate the cyclic behavior of non-cohesive soils (sands and silts), under any (smallmedium-large) cyclic shear strain amplitude using a single (sand-specific) set of constants, irrespective of the initial stress and density conditions. It is based on a previously proposed model ([6], [7]), but in its current form it is characterized by a vanished elastic region. In addition, it incorporates three (3) open cone-type surfaces with apex at the origin of stress space: (i) the Critical State surface at which deformation develops for fixed stresses and zero volumetric strain, (ii) the Bounding surface which locates the (ever-current) peak stress ratio states and (iii) the Dilatancy surface which dictates the sign of the plastic volumetric strain rate during loading. The NTUA-SAND model has been extensively validated against centrifuge experiments related to a number of different liquefaction-related problems: lateral spreading ([8]), foundation settlement ([9]), pile response ([10]), use of drains for liquefaction mitigation ([11]). As such it considered very reliable for the task at hand in this paper.

As shown in Figure 1, the liquefiable soil layer has a thickness $H=10 \mathrm{~m}$, while the strip footing width is $\mathrm{B}=5 \mathrm{~m}$. In order to ensure no effects from the boundaries, the soil layer has a total width of $100 \mathrm{~m}$. This soil domain is discretized into 1000 rectangular zones (the "elements" in FLAC terminology). The mesh is denser in the vicinity of the footing (for an ap- 
proximate width of $2.0 \mathrm{~B}=10 \mathrm{~m}$ ), reaching a zone thickness equal to $0.5 \mathrm{~m}$. The footing is considered massless, rigid and rough, and is simulated by beam elements on the top of the mesh. The same mesh is also used for the analyses that considered improvements at the perimeter of the footing. Specifically, a row of elements (of $0.5 \mathrm{~m}$ thickness) has either a permeability coefficient 1000 times larger than that of the natural soil (prefabricated drains) or was considered elastic with very increased stiffness (diaphragm walls, made of reinforced concrete). As also shown in Figure 1, this row of elements was considered at a distance of $0.5 \mathrm{~m}$ from the edge of both sides of the footing, while the effects of the depth of the improvement $\mathrm{H}_{\text {imp }}$ was studied parametrically as part of this study.

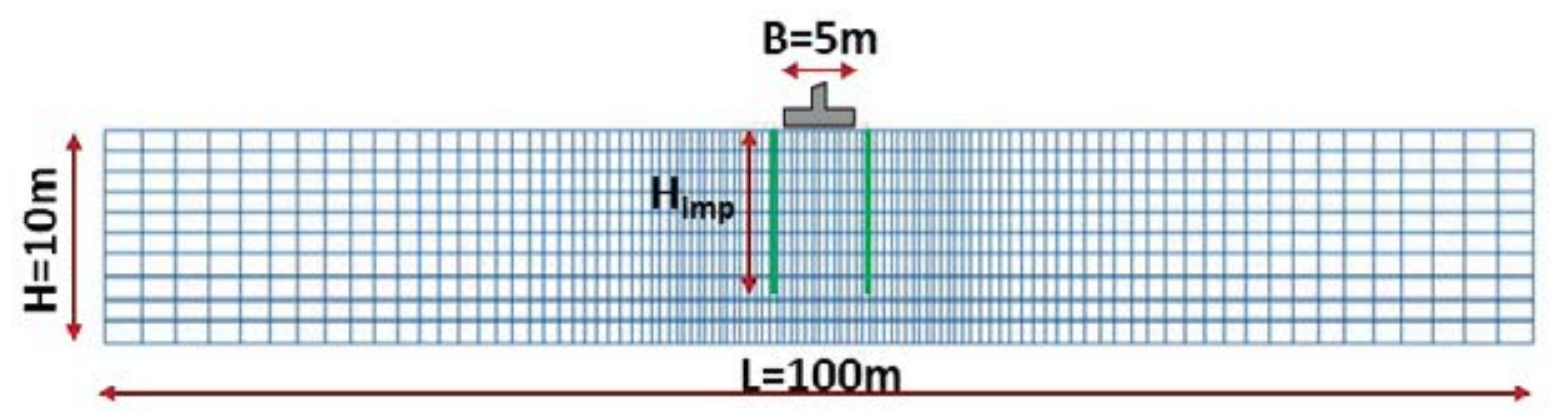

Figure 1: Basic definitions and dimensions of the numerical simulation model (horizontal ground).

The liquefiable soil is (fine) Nevada sand of relative density $\mathrm{D}_{\mathrm{r}}=45 \%$, dry density $1.53 \mathrm{Mgr} / \mathrm{m}^{3}$, void ratio 0.718 and permeability $\mathrm{k}=6.5 \times 10^{-5} \mathrm{~m} / \mathrm{s}$. This is considered in the analyses via the values of the NTUA-SAND model constants, as adopted from numerous successful simulations using this sand in the literature (e.g., [3], [4], [8], [9], [10], [11]). A uniform vertical load of $100 \mathrm{kPa}$ is applied to the footing in all numerical analyses presented herein. The base excitation is an acceleration time history that is sinusoidal, consisting of ten (10) main cycles with period $\mathrm{T}=0.35 \mathrm{~s}$ and maximum acceleration $\mathrm{a}_{\max }=0.20 \mathrm{~g}$. Two (2) additional cycles of variable acceleration have been added to the start and the end of the acceleration time-history to ensure gradual increase and decrease of the acceleration. The lateral boundaries of the model that are at the same altitude are tied to one-another to ensure that they will have the same horizontal displacements throughout the excitation, thus simulating the shaking behavior of a laminar box container, or the free field response insitu.

For the numerical simulation of footings resting on mildly inclined ground (angle $i=2^{\circ}$ ), the same grid has been used with the following adjustments:

- the gravity vector has been rotated by $2^{\circ}$ to simulate the sloping ground (see [8] for details)

- a minor "excavation" has been modeled at the footing location, to ensure the footing rests on horizontal ground, despite the inclination of the sloping ground

In addition, for reference purposes, the inclined ground response analysis without the existence of footing (lateral spreading of soil at the free-field) is also performed and denoted as free-field (FF) herein.

\section{TYPICAL STRUCTURAL RESPONSE ON LIQUEFIABLE SAND}

As it was expected, the performed numerical analyses verify the severe problems caused by the existence of a liquefied sand layer of significant thickness underneath existing structures. The developed "failure" mechanism of each footing in the liquefied soil can be deduced from Figure 2, where the accumulated shear strains in the soil underneath the footing at the end of shaking are shown, both for horizontal (subplot 2a) and (mildly) inclined (subplot 2b) ground conditions. 
(a)

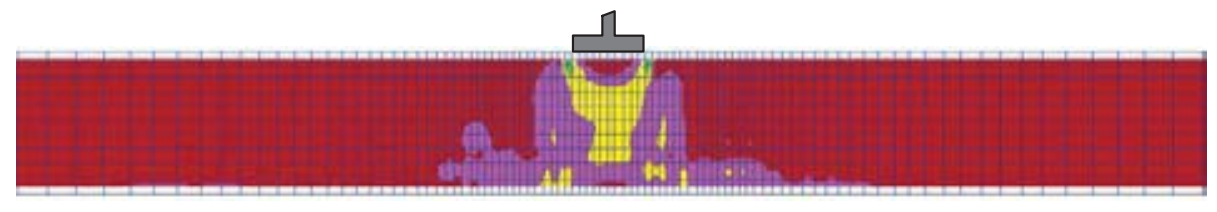

(b)
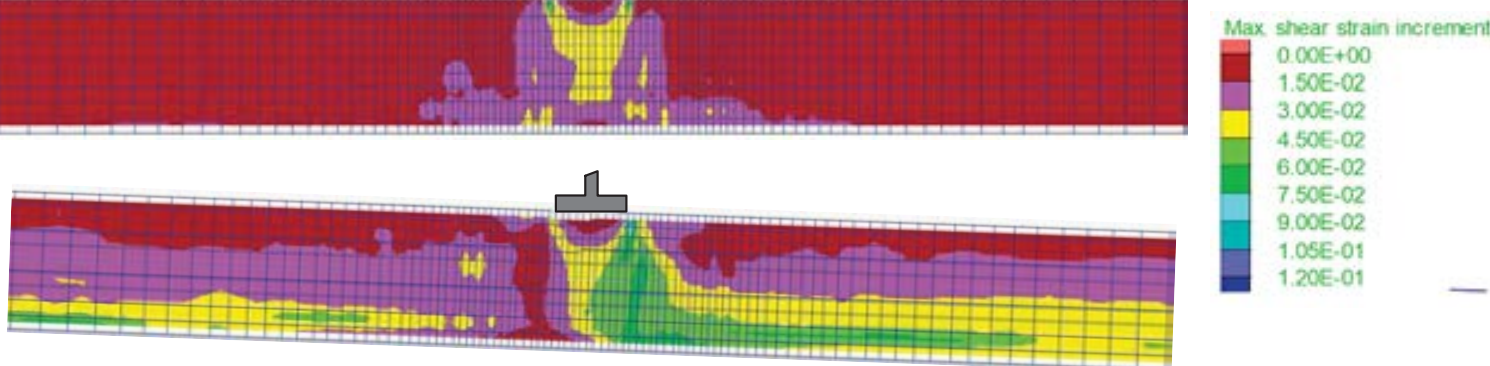

Figure 2: Accumulated shear strains underneath strip footings of width $B=5 \mathrm{~m}$ (at the end of shaking) resting on liquefied ground of thickness $\mathrm{H}=10 \mathrm{~m}$ that is: (a) horizontal and (b) inclined by $2^{\circ}$

In horizontal ground conditions (Figure 2a) the shear strains concentrate in the area beneath the strip footing, creating a "punching" failure mechanism that reaches the bottom of the liquefied layer (at depth 2.0B here) without extending laterally. This "failure" mechanism is narrower and deeper than the well-known bearing capacity mechanism of footings in nonliquefied soils (generalized failure in the shape of a logarithmic spiral), which extends to distances up to $3.5 \mathrm{~B}$ to $5.0 \mathrm{~B}$ laterally and down to $1.5 \mathrm{~B}$ in depth. When the same footing rests on a mildly inclined ground surface, the punching "failure" mechanism reaches again the bottom of the liquefied layer, but is no longer symmetrical (see Figure 2b). Particularly, the zone of intense shearing is more pronounced towards the downslope side and is connected to the shear band that appears at the base of the liquefied layer due to lateral spreading.

In order to gain further insight into the structural response, Figure 3 presents the timehistories of footing displacement (horizontal $\mathrm{x}$ and vertical $\mathrm{z}$ ) and rotation $(\theta)$ during the excitation, for both horizontal and inclined ground conditions. Particularly, in Figure $3 \mathrm{a}$ the horizontal displacement of the footing resting on inclined ground is being presented (blue line) in comparison with the horizontal displacement of the ground surface of the corresponding freefield laterally spreading layer (dashed green line), under the same excitation. The positive sign depicts downslope displacements. The figure shows that in both cases the horizontal displacements accumulate linearly with time, or with the number of sinusoidal excitation cycles. In quantitative terms, the footing is carried away by the laterally spreading of the liquefied ground, since the footing displacement is practically identical to that of the free field displacement. Hence, despite that the footing increases the vertical stresses in the ground below its footprint, the procuring local increase of shear strength does not suffice for reducing the horizontal drift of the footing. It is believed that this response is the worst-case scenario for a footing and it is due to its relatively small width $\mathrm{B}$ in comparison to the thickness $\mathrm{H}$ of the liquefied layer, that takes a value of $\mathrm{B} / \mathrm{H}=0.5$ here. In other cases where $\mathrm{B} / \mathrm{H}>1$, it is expected that the footing drift would be smaller than the horizontal displacement of the ground surface of the corresponding free-field laterally spreading layer.

In addition, Figure $3 \mathrm{~b}$ presents the accumulated settlement of the (centerline of the) footings in both horizontal (purple line) and inclined (blue line) ground conditions, under the same excitation. It is observed that the settlement of the footing on the inclined layer is of the same magnitude (actually slightly larger) with that of the same footing if the layer is horizontal. This means that the existence of a mild ground inclination does not significantly affect the settlement response. Note also that the final settlement value is in the order of $25-27 \mathrm{~cm}$, i.e., much smaller than the $48 \mathrm{~cm}$ of horizontal displacement of the footing. Finally, Figure $3 \mathrm{c}$ presents the rotation of the rigid footing resting on the inclined layer during the excitation, with the negative value of $\theta$ depicting downslope rotation, i.e., clockwise rotation for the case of Figure 2b. 

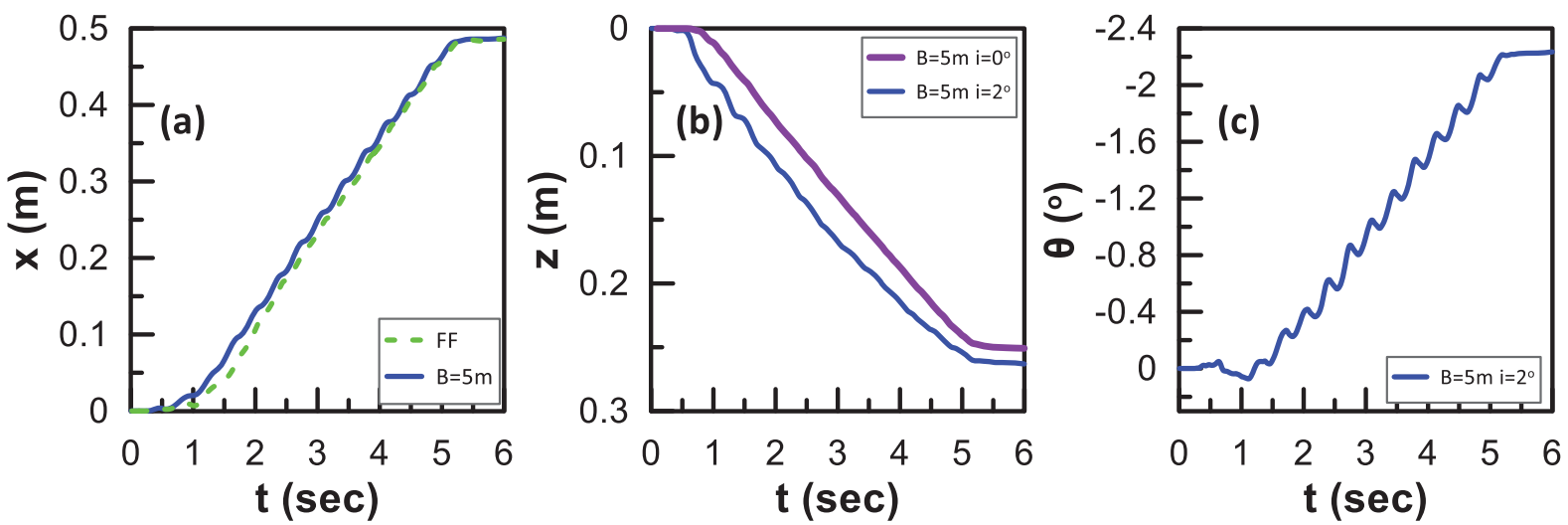

Figure 3: Time-histories of response characteristics of strip footing of width $B=5 \mathrm{~m}$ on liquefied ground with $\mathrm{H}=10 \mathrm{~m}$ that is horizontal or inclined, in terms of: (a) horizontal displacement, (b) settlement, and (c) rotation.

There is no other curve in Figure $3 \mathrm{c}$ for comparison purposes, since the footing in horizontal ground does not rotate (due to zero static eccentricity). Observe that the rotation also accumulates linearly with time and its final value of $\theta=2.2^{\circ}$ is quite significant, i.e., slightly larger than the ground inclination of $2^{\circ}$. As was the case for horizontal displacements, this large value of $\theta$ is also due to the small $\mathrm{B} / \mathrm{H}$ ratio that allows for easier rotations, in comparison to cases with $\mathrm{B} / \mathrm{H}>1$ that are expected to rotate less under the same excitation.

Overall, Figure 3 shows that the existence of a mild ground inclination (just $2^{\circ}$ in our case) leads to the added hazard of (significant) horizontal displacement and rotation of the structure due to the lateral spreading of the liquefied layer. Hence, such large combined rigid body translations of the structure cannot be safely accommodated by any structural system and the need for soil improvement is more pronounced than for horizontal ground conditions.

\section{MITIGATION WITH PERIMETRICAL PREFABRICATED DRAINS}

The first improvement technique for existing structures examined here is the application of dense rows of prefabricated drains at the perimeter of an existing footing, which for a strip footing corresponds to the area denoted with green color in Figure 1. This configuration is inspired by pertinent centrifuge tests [1] and aims at reducing the developing excess pore pressures beneath the footing. In our analyses, the drains are considered to extend to the bottom of the liquefied layer, i.e., $\mathrm{H}_{\mathrm{imp}}=\mathrm{H}=10 \mathrm{~m}$. For the purpose of the numerical simulation, the permeability of the elements at the improved zone has been considered to be 1000 times higher than that of the natural sand, i.e., it is considered equal to $\mathrm{k}=6.5 \times 10^{-2} \mathrm{~m} / \mathrm{s}$. Note that the improvement area of width $0.5 \mathrm{~m}$ simulates the effective area of dense series of prefabricated drains (each one of which has a small diameter of a few $\mathrm{cm}$ ), which as a system offers the foregoing drainage capability to the natural sand. Since the drains are not made of gravel, the response is only affected in terms of drainage. Hence, the constitutive model for the improvement area is still the NTUA-SAND model calibrated identically to the natural sand.

In order to study the effectiveness of this liquefaction mitigation technique, Figure 4 presents the time-histories for the footing displacements $\mathrm{x}$ and $\mathrm{z}$ and rotations $\theta$ with and without the perimetrical prefabricated drains. The results for the cases with drains are different when the liquefiable layer is horizontal (khaki line with spikes) and inclined (green line with crosses). More specifically, Figure 4a presents the comparison in terms of horizontal displacement $x$ of the footing, where only a minor decrease is obtained (approximately 10\%) with the installation of the perimetrical drains. Similar conclusions are derived in Figure $4 \mathrm{~b}$ for the footing settlements, only that the reduction in seismic settlements is approximately $20 \%$ for both horizontal and inclined ground surface conditions. 

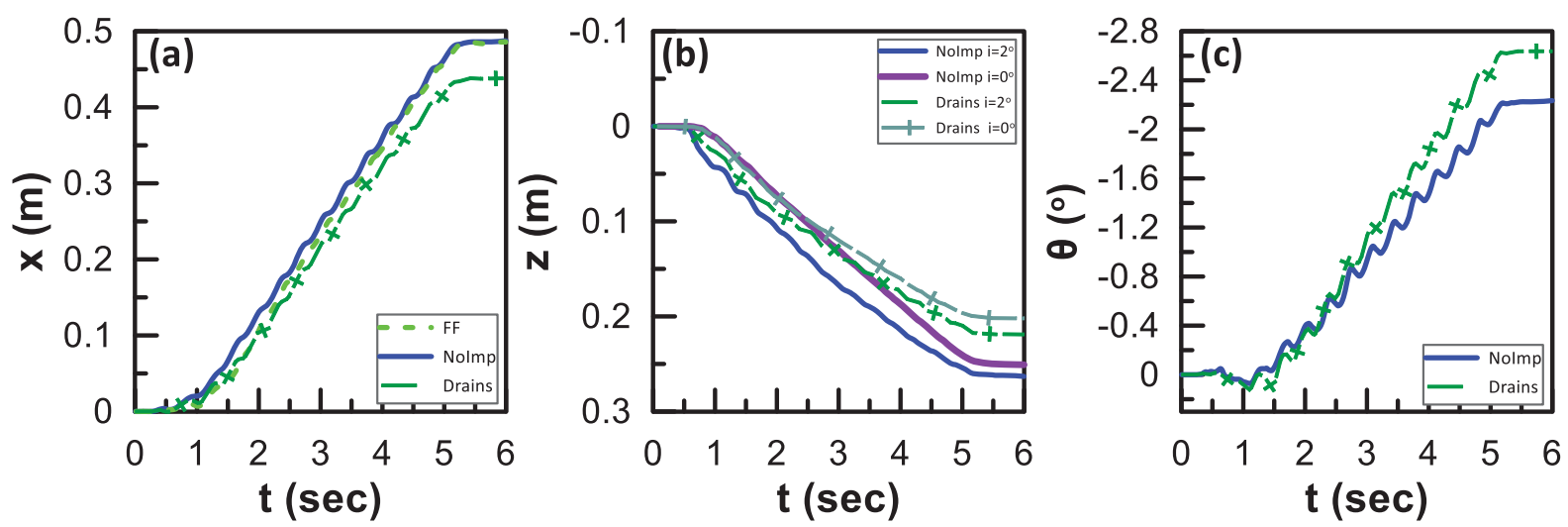

Figure 4: Effect of perimetrical drains on time-histories of response characteristics of strip footing of width $\mathrm{B}=$ $5 \mathrm{~m}$ on liquefiable ground with $\mathrm{H}=10 \mathrm{~m}$ that is horizontal or inclined, in terms of: (a) horizontal displacement, (b) settlement and (c) rotation.

Unfortunately, these small benefits in reduced footing displacements come at a price of increased footing rotations (in the order of $20 \%$ ) in the case of laterally spreading inclined sand, as depicted in Figure 4c.

Overall, solely perimetrical drains do not seem to offer any significant benefit in the footing response, while they may even be considered unfavorable if rotations are of primary concern. Either positive or negative, the effects of such drains on the footing response are quantitatively small. This is corroborated by the images of accumulated shear strains in the foundation soil at the end of shaking, that are presented in Figure 5, for both horizontal (in subplot 5a) and inclined (in subplot 5b) ground conditions in the presence of perimetrical drains. Specifically, if one compares these images with the respective plots in Figure 2, a great resemblance is depicted. For example, observe the "punching" failure mechanism when the soil is horizontal in both cases for horizontal ground (subplots $2 \mathrm{a}$ and 5a). Also observe that when the soil is mildly inclined, the foregoing failure mechanism becomes asymmetrical and (roughly) connected to the shear band at the base of the liquefied layer due to lateral spreading in the downslope slide of the footing, regardless of whether perimetrical drains are implemented (subplot 5b) or not (subplot $2 b$ ).

In closing, it is underlined here that this inefficient liquefaction mitigation is a result of the inability of the solely perimetrical drains to effectively reduce the excess pore pressures below the footing. If it was possible to implement drains throughout the area below the footing, the resulting liquefaction mitigation would be more efficient. However, such configuration can only be implemented before the construction of a new footing, and not below existing structures that is the aim of this investigation.

(a)

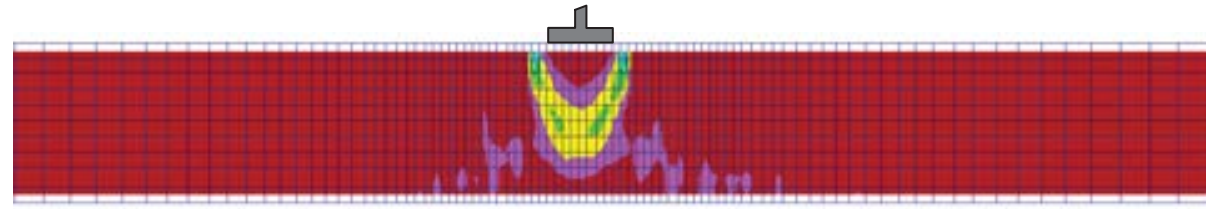

(b)
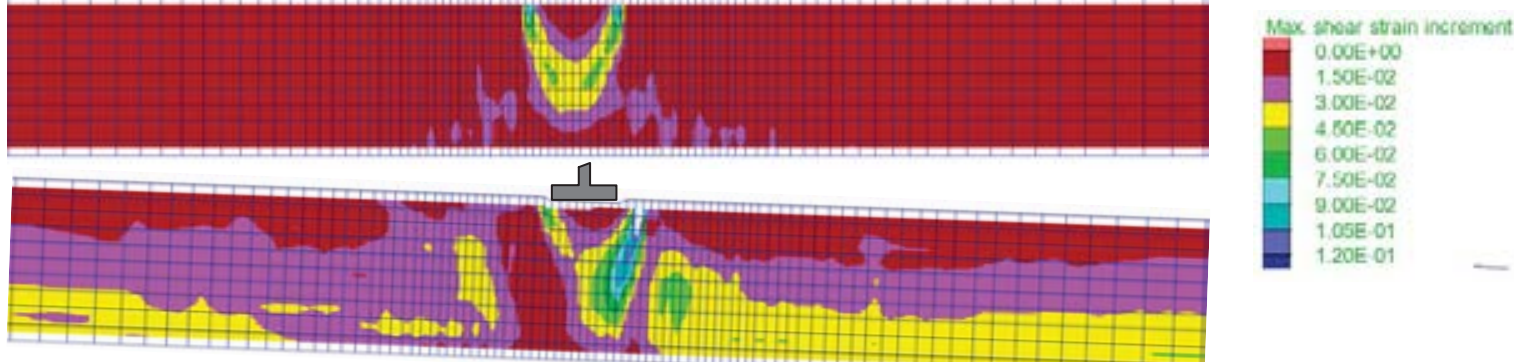

Figure 5: Accumulated shear strains underneath strip footings of width $\mathrm{B}=5 \mathrm{~m}$ with perimetrical drains (at the end of shaking) resting on liquefiable sand of thickness $\mathrm{H}=10 \mathrm{~m}$ that is: (a) horizontal and (b) inclined by $2^{\circ}$ 


\section{MITIGATION WITH PERIMETRICAL DIAPHRAGM WALLS}

The second technique investigated for the mitigation of liquefaction underneath an existing structure is the construction a stiff containment wall at its perimeter and within the foundation soil (see concept in Figure 1, as inspired by [2]). This wall retains the soil underneath the structure in place, while increasing the overall stiffness of the foundation system. The construction material of this wall may vary, but in the analyses presented herein it is considered to be reinforced concrete. In this respect, these containment walls are named diaphragm walls. Two different wall lengths are examined, a) full-depth wall, from the ground surface to the bottom of the liquefiable layer $\left(\mathrm{H}_{\mathrm{imp}}=\mathrm{H}=10 \mathrm{~m}\right)$, b) half-depth wall, from the ground surface to the mid-depth of the liquefiable layer $\left(\mathrm{H}_{\mathrm{imp}}=\mathrm{H} / 2=5 \mathrm{~m}\right)$. The full-depth walls are considered pinned to the base of the mesh, thus following the base excitation, while the mid-depth walls are considered floating inside the liquefiable layer. The retaining wall of $0.5 \mathrm{~m}$ thickness is simulated with an elastic model of bulk modulus equal to $16.7 \mathrm{GPa}$, shear modulus equal to $12.5 \mathrm{GPa}$, mass density $2.50 \mathrm{Mgr} / \mathrm{m}^{3}$ and are practically impermeable (in our analyses a permeability of $6.7 \times 10^{-7} \mathrm{~m} / \mathrm{s}$ is considered, i.e., 100 times lower than that of the surrounding soil).

In order to study the effectiveness of this liquefaction mitigation technique, Figure 6 presents the time-histories for the footing displacements $\mathrm{x}$ and $\mathrm{z}$ and rotations $\theta$ with and without the perimetrical full-depth diaphragm walls. In order to distinguish the results for the cases with these walls, those pertaining to the horizontal liquefiable layer are depicted by a red line with quotations, while those that refer to the inclined layer with a purple line with squares. Interestingly, the construction of the walls seems to offer maximum improvement, since all footing response characteristics (displacements $\mathrm{x}, \mathrm{z}$ and rotation $\theta$ ) become essentially zero, regardless of whether the liquefiable layer is horizontal or not.
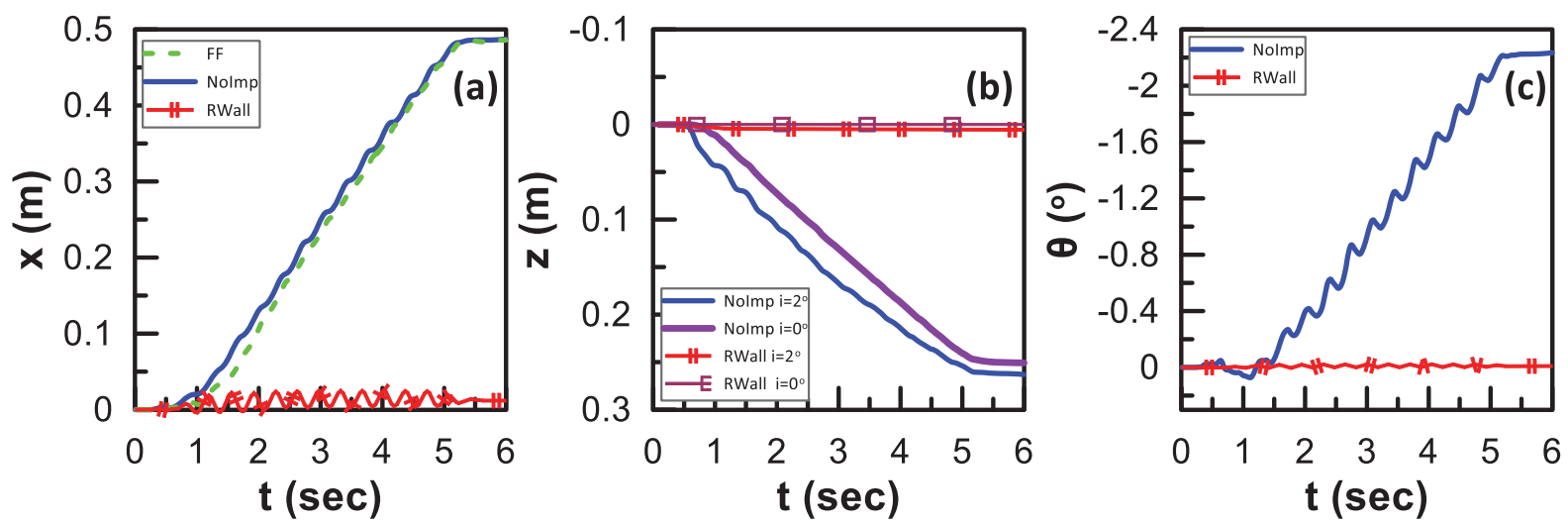

Figure 6: Effect of full-depth $\left(\mathrm{H}_{\mathrm{imp}}=10 \mathrm{~m}\right)$ perimetrical diaphragm walls on time-histories of response characteristics of strip footing of width $\mathrm{B}=5 \mathrm{~m}$ on liquefiable ground with $\mathrm{H}=10 \mathrm{~m}$ that is horizontal or inclined, in terms of:

(a) horizontal displacement, (b) settlement and (c) rotation.

This impressive performance of the full-depth diaphragm walls is corroborated by the images of accumulated shear strains in the foundation soil at the end of shaking, that are presented in Figure 7 for both horizontal (in subplot 7a) and inclined (in subplot 7b) ground conditions in the presence of such walls. Specifically, if one compares these images with the respective plots in Figure 2, a totally different response is depicted. For horizontal ground, there are no shear bands formed underneath the footing, thus explaining the zero footing settlements. On the contrary, shear bands are formed in the inclined ground. Specifically, the uphill shear band is related to the laterally spreading sand layer that drifts towards the footing area. This soil movement is hindered by the uphill rigid wall, thus leading to upward relative movement of the soil against it, which in turn creates a shear band at the interface. 


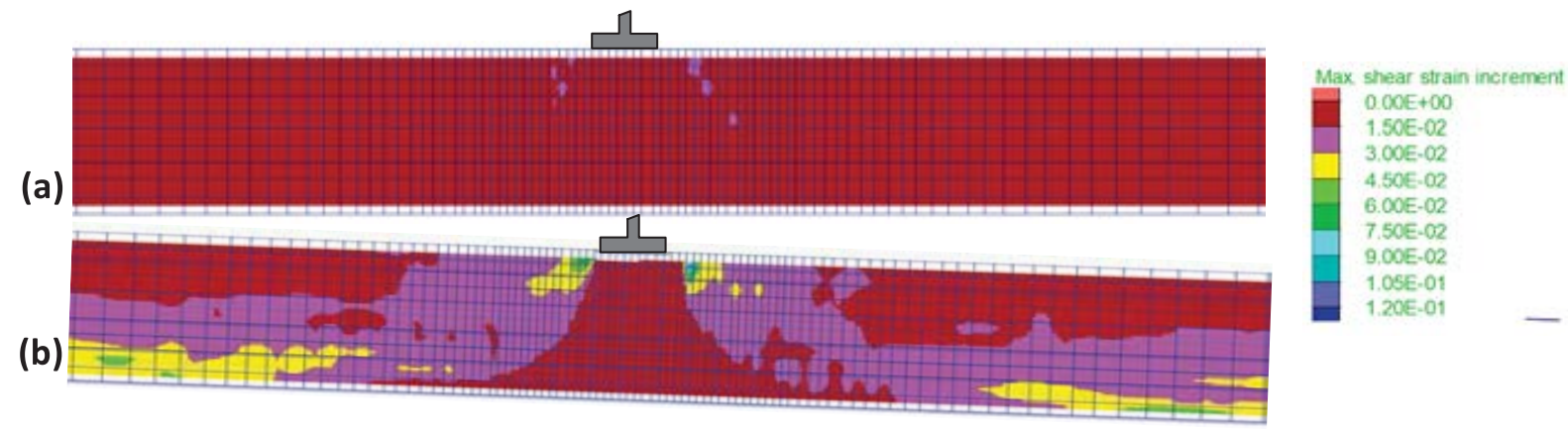

Figure 7: Accumulated shear strains underneath strip footings of width $\mathrm{B}=5 \mathrm{~m}$ with (full-depth $\mathrm{H}_{\mathrm{imp}}=10 \mathrm{~m}$ ) perimetrical diaphragm walls (at the end of shaking) resting on liquefiable sand of thickness $\mathrm{H}=10 \mathrm{~m}$ that is: (a) horizontal and (b) inclined by $2^{\circ}$

Similarly, the downhill shear band is related to the laterally spreading sand layer that drifts away from the footing area. As this soil mass moves, there is downward relative movement of the soil versus the downhill rigid wall, thus creating the pertinent shear band at their interface. It becomes evident that these shear bands have no effect on the footing response itself since they are formed outside the walls and not underneath the footing. As such, zero displacements and rotation appear in the unaffected footing.

It has to be underlined here that the rigidity of the diaphragm walls is key for this excellent performance. In other words, if these full-depth containment walls are constructed with a less stiff material (e.g., deep soil mixing with cement, or lime), then their performance is not expected to be as excellent, i.e., some settlements or rotations of the footing may persist. Another issue of importance is how the depth of the diaphragm walls affects the footing response. This is the reason that analyses with half-depth perimetrical diaphragm walls are performed herein. Their efficiency is explored in Figure 8 that presents the time-histories for the footing displacements $\mathrm{x}$ and $\mathrm{z}$ and rotations $\theta$ with and without these half-depth walls in the format of Figure 6. Interestingly, the operation of these half-depth walls does not seem as effective as that of its full-depth counterparts. Specifically, these half-depth walls manage to reduce horizontal displacement $x$ (in subplot $8 \mathrm{a}$ ) by just $10 \%$, settlements $\mathrm{z}$ by $20 \%$ (in subplot $8 \mathrm{~b}$ ) and downhill rotations by $75 \%$ (in subplot $8 \mathrm{c}$ ). In other words, the half-depth walls seem significantly effective only for the reduction of footing rotations in cases that the sand layer is mildly inclined. For the footing (horizontal and vertical) displacements, these walls appear to offer improvement that is comparable to that of full-depth perimetrical drains.

In order to understand the reasons behind this significantly reduced effectiveness of halfdepth diaphragm walls, images of accumulated shear strains in the foundation soil at the end of shaking are presented in Figure 9 for both horizontal (in subplot 9a) and inclined (in subplot 9b) ground conditions. Observe in subplot 9a that the soil mass in between the diaphragm walls and under the footing seems to move downwards as a rigid block (creating shear bands in the inner interfaces of the walls), thus translating the "punching" bearing capacity failure in the lower half of the liquefied layer where the diaphragm walls do not reach. Similarly, in subplot $9 \mathrm{~b}$, the shear band at the bottom of the laterally spreading soil layer seems little affected by the existence of the half-depth walls, thus explaining their inability to reduce the horizontal drift of the footing. In addition, the clear asymmetry of the failure mechanism under the footing that appears in the untreated case (see Figure $2 b$ ) seems less pronounced in the case of the half-depth walls of subplot $9 \mathrm{~b}$, an observation that may explain the smaller (yet non-zero) rotations of the footing when half-depth walls are in place. 

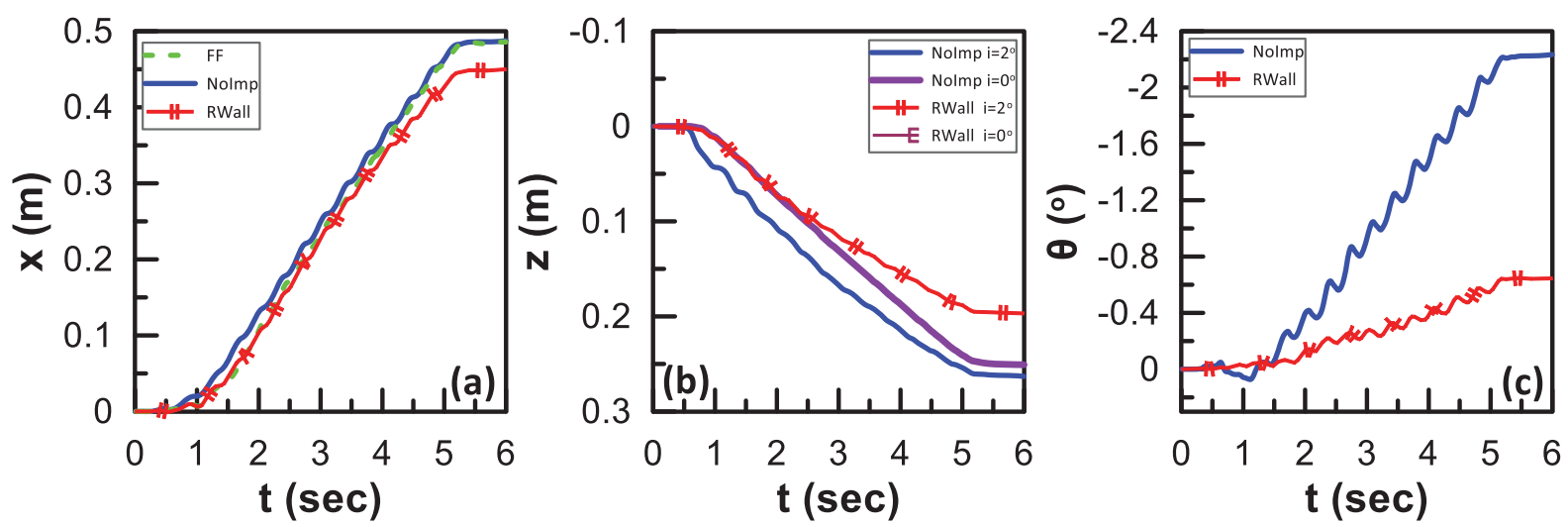

Figure 8: Effect of half-depth $\left(\mathrm{H}_{\mathrm{imp}}=5 \mathrm{~m}\right)$ perimetrical diaphragm walls on time-histories of response characteristics of strip footing of width $\mathrm{B}=5 \mathrm{~m}$ on liquefiable ground with $\mathrm{H}=10 \mathrm{~m}$ that is horizontal or inclined, in terms of:

(a) horizontal displacement, (b) settlement and (c) rotation.

(a)

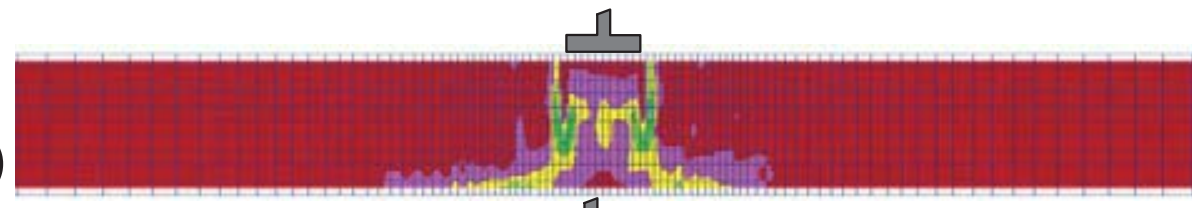
几

(b)
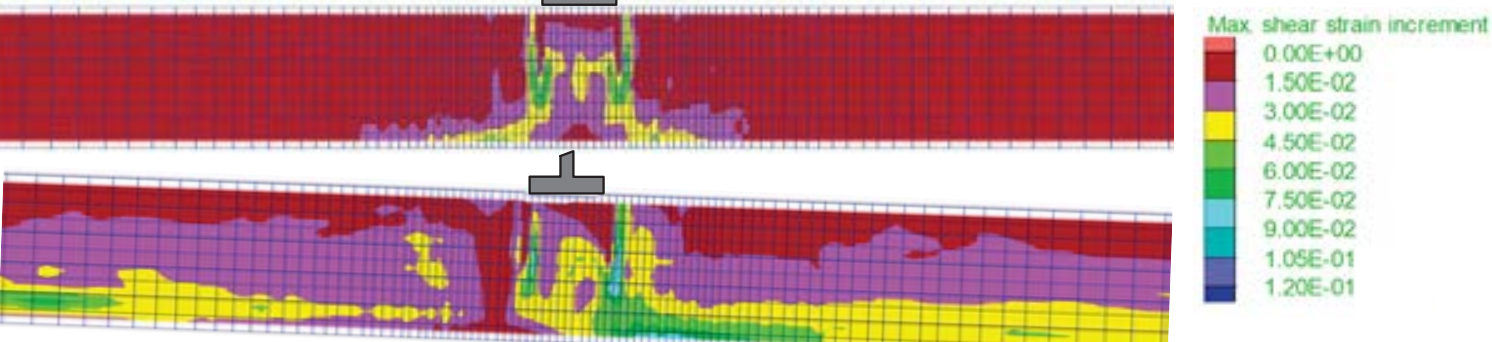

Figure 9: Accumulated shear strains underneath strip footings of width $B=5 \mathrm{~m}$ with (half-depth $\left.\mathrm{H}_{\mathrm{imp}}=5 \mathrm{~m}\right)$ perimetrical diaphragm walls (at the end of shaking) resting on liquefiable sand of thickness $\mathrm{H}=10 \mathrm{~m}$ that is: (a) horizontal and (b) inclined by $2^{\circ}$.

\section{CONCLUSIONS}

Fully coupled numerical analyses are performed in order to examine the response of shallow-founded structures on horizontal and/or mildly inclined liquefiable layers of relatively significant thickness. The results show that besides significant settlements, even a very mild slope $\left(2^{\circ}\right.$ here $)$ creates lateral spreading, which in turn causes the additional hazard of similarly large horizontal displacements and rigid body downhill rotations of the structure.

Then, the efficiency of two liquefaction mitigation methods that can be readily implemented in existing structures resting on the foregoing layers is examined numerically. Specifically, the use of prefabricated drains at the perimeter of the structure does not prove efficient, since it reduces by $10-20 \%$ its horizontal displacements and settlements, but may even increase slightly its rotations. On the contrary, the implementation of reinforced concrete perimetrical walls with depth until the bottom of the liquefiable layer proves exceptionally efficient, since all structural displacements and rotations become zero. The investigation also shows that this efficiency disappears if the perimetrical walls are shallower than the bottom of the liquefiable layer. For example, if these walls reach the mid-depth of the liquefiable layer, the perimetrical diaphragm walls become similarly efficient as the perimetrical drains.

\section{ACKNOWLEDGMENTS}

This research is carried out / funded in the context of the project "Applicability of seismic liquefaction mitigation via nano-material injection under existing infrastructures" (MIS 5049429) under the call for proposals "Researchers' support with an emphasis on young re- 
searchers- 2nd Cycle". The project is co-financed by Greece and the European Union (European Social Fund- ESF) by the Operational Programme Human Resources Development, Education and Lifelong Learning 2014-2020.

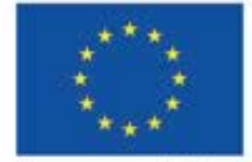

European Union European Social Fund
Operational Programme Human Resources Development, Education and Lifelong Learning

Co-financed by Greece and the European Union

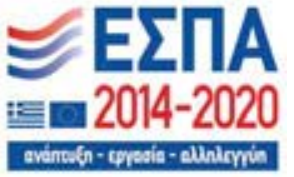

\section{REFERENCES}

[1] B. Paramasivam, S. Dashti, A. Liel, Influence of prefabricated vertical drains on the seismic performance of structures founded on liquefiable soils, Journal of Geotechnical and Geoenvironmental Engineering, ASCE, 144, no. 10, 04018070, 2018

[2] H. Mitrani, S.P.G. Madabhushi, Rigid containment walls for liquefaction remediation, Journal of Earthquake and Tsunami, 6, No. 2, 1250017, 2012

[3] Itasca Consulting Group Inc., Fast Lagrangian Analysis of Continua, 2011.

[4] K.I. Andrianopoulos, A.G. Papadimitriou, G.D. Bouckovalas, Explicit integration of bounding surface model for the analysis of earthquake soil liquefaction, International Journal for Numerical and Analytical Methods in Geomechanics, 34(15): 1586-1614, 2010

[5] K.I. Andrianopoulos, A.G. Papadimitriou, G.D. Bouckovalas, Bounding surface plasticity model for the seismic liquefaction analysis of geostructures, Soil Dynamics and Earthquake Engineering, 30(10): 895-911, 2010

[6] A.G. Papadimitriou, G.D. Bouckovalas, Y.F. Dafalias, Plasticity model for sand under small and large cyclic strains, Journal of Geotechnical and Geoenvironmental Engineering, $A S C E$, 127, no. 11, 973-983, 2001

[7] A.G. Papadimitriou, G.D. Bouckovalas, Plasticity model for sand under small and large cyclic strains: a multiaxial formulation, Soil Dynamics and Earthquake Engineering 22 (3), 191-204, 2002.

[8] A.I. Valsamis, G.D. Bouckovalas, A.G. Papadimitriou, Parametric investigation of lateral spreading of gently sloping liquefied ground, Soil Dynamics and Earthquake Engineering 30 (6), 490-508, 2010.

[9] D.K. Karamitros, G.D. Bouckovalas, Y.K. Chaloulos, K.I. Andrianopoulos, Numerical analysis of liquefaction-induced bearing capacity degradation of shallow foundations on a two-layered soil profile, Soil Dynamics and Earthquake Engineering 44, 90-101, 2013.

[10] A.I. Valsamis, G.D. Bouckovalas, Y.K. Chaloulos, Parametric analysis of single pile response in laterally spreading ground Soil Dynamics and Earthquake Engineering 34 (1), 99-110, 2012.

[11] A. G. Papadimitriou, M.-E. Moutsopoulou, G. D. Bouckovalas, A. J. Brennan, Numerical investigation of liquefaction mitigation using gravel drains, Proceedings, $4^{\text {th }}$ International Conference on Earthquake Geotechnical Engineering, Thessaloniki, June 2528, Paper 1548, 2007. 